\title{
Mood and anxiety disorders adversely influence medication adherence to antiretroviral therapy among people living with HIV/AIDS in Nigeria
}

\author{
Omonefe Seb-Akahomen, Ambrose Lawani, Bawo James \\ Federal Neuro-Psychiatric Hospital, Benin-City, Edo State, Nigeria
}

\begin{abstract}
Introduction: Psychological disorders in HIV/AIDS are well documented. However, studies enumerating its impact on medication adherence are scanty in developing countries. This study sought to determine the collective impact of mood and anxiety disorders on medication adherence among persons living with HIV/AIDS (PLWHA), receiving care at a secondary health care facility in Benin-City, Nigeria.

Material and methods: A cross-sectional descriptive study of 410 PLWHA was conducted between April and August 2015. A semi-structured socio-demographic and clinical history study questionnaire, the 8-item Morisky medication adherence scale (MMAS-8) to determine medication adherence to highly active antiretroviral therapy (HAART), and the mini international neuropsychiatric interview (MINI) to diagnose mood and anxiety disorders were administered to participants.

Results: One hundred and fifty-one participants (36.8\%) were poorly adherent to their medications, with nearly 1 in $3(31.5 \%)$ diagnosed with a mood or anxiety disorder. On bivariate analysis, poor medication adherence was significantly associated with low $\left(<200 \mathrm{cell} / \mathrm{mm}^{3}\right) \mathrm{CD} 4$ cell count $($ crude $\mathrm{OR}=3.23$; 95\% CI: 1.81-5.80; $p<0.001$ ) and having a mood or anxiety disorder (crude OR $=17.89$; 95\% CI: $10.28-31.38 ; p<0.001)$. The presence of a mood/anxiety disorder predicted poor adherence $(\mathrm{AOR}=16.45$; 95\% CI: 9.69-27.92; $p<0.001)$ on multivariate analysis.

Conclussions: Mood and anxiety disorders in PLWHA are common and are associated with poorer medication adherence. Further research is required to assess if screening and management of mood and anxiety disorders would improve medication adherence.
\end{abstract}

HIV AIDS Rev 2018; 17, 2: 91-97

DOI: https://doi.org/10.5114/hivar.2018.76368

Key words: medication adherence, mood and anxiety disorders, HIV/AIDS, Nigeria.

\section{Introduction}

About 35.3 million people live with HIV/AIDS worldwide with a majority living in sub-Saharan Africa [1]. In Nigeria, the prevalence rate of HIV/AIDS is 3.4\% [2], which translates

to about 6.3 million people living with the disease [3]. HIV/ AIDS remains a major public health problem in the country.

Available evidence reveals a significant association between mental disorders and HIV/AIDS [4-6]. Mood and anxiety disorders are commonly diagnosed in people living with

Article history:

Received: 22.06.2017

Received in revised form: 14.01.2018

Accepted: 16.01.2018

Available online: 21.05.2018
International Journal of HIV-Related Problems

HIV \& AIDS

R e v i e w 
HIV/AIDS (PLWHA), in excess of rates in the general population $[4,7,8]$; the prevalence rates however, differs across studies [9-12]. Varied ascertainment criteria, study design, and population characteristics may account for the disparity in rates [4]. Mood and anxiety disorders are associated with poor adherence to medication [13] and poorer quality of life $[14,15]$.

Poor adherence to antiretroviral therapy (ART) is associated with failure to prevent viral replication, increased likelihood of developing viral resistance, development of clinical complications, and reduced life expectancy $[16,17]$. In addition, psychiatric morbidity worsens adherence to highly active antiretroviral therapy (HAART) amongst PLWHA [18-22].

This study aimed to elucidate the prevalence and pattern of mood and anxiety disorders among PLWHA receiving care at a secondary health care facility in Benin-City, Nigeria. Since previous studies from sub-Saharan Africa have focused on depression and anxiety symptoms, we also sought to assess adherence using a validated self-report tool as well as to confirm the relationship between having a mood or anxiety disorder and poor adherence to HAART.

\section{Material and methods}

\section{Study design}

This was a cross-sectional observational study of PLWHA receiving out-patient care at a secondary health care facility in Benin-City, Nigeria.

\section{Setting}

The study was conducted at the Out-Patient HIV Clinic of the Central Hospital, Benin-City, Nigeria. This facility was chosen because the records, as at the time this study was conducted, showed that it offers free screening, medication, and counselling to a population of 10,000 PLWHA in or around the city. Free treatment removes cost of care, which is often a barrier to access care, and the cohort is a reflection of population with the illness in the area.

\section{Study participants}

To be included in the study, participants must have been aged between 18 and 64 years, confirmed with a diagnosis of HIV/AIDS, provide signed written consent, and must have been on HAART for at least 3 months prior to the study interview. Inability to communicate in English or experiencing an acute illness episode or complication, which would impair participants ability to understand the nature of the study or make appropriate responses were exclusion factors.

\section{Data collection}

All socio-demographic and clinical history data were obtained using a semi-structured study questionnaire designed by the researchers, detailing socio-demographic variables such as: age, gender, marital status, ethnicity, employment status, place of residence, educational status, religion, and estimated monthly income and clinical variables. Last recorded CD4 count, year of diagnosis, duration on HAART, and presence of physical co-morbidity were also verified.

\section{Diagnoses of mood and anxiety disorders}

The mini international neuro-psychiatric interview (MINI) version 5.0.0 was used to screen and diagnose mood or anxiety disorders. The modules for mood and anxiety disorders were utilized for this process. The MINI is a brief structured interview for the major axis I psychiatric disorders of DSM-IV and ICD-10 [23]. It has been used previously in studies conducted in Nigeria $[8,24,25]$.

\section{Assessing medication adherence}

The eight-item Morisky medication adherence questionnaire (MMAS-8) [26] was administered to participants to assess self-reported adherence to HAART. We chose to administer the MMAS- 8 to overcome knowledge barrier from participants who could communicate in English language but had difficulty reading or writing. The MMAS-8 though initially validated hypertensive persons and has been used for adherence measurement in a wide variety of medical conditions. Each item on MMAS-8 measures a specific medication-taking behavior in a dichotomous 'yes' or 'no' format, with a 5-point Likert response for the last item. The total scores are trichotomized into 'high' (MMAS score of 8), 'moderate' (MMAS score of 6 and 7), or 'low' (MMAS score of less than 6). The MMAS has been used in psychiatric and other medical settings within and outside Nigeria [27, 28].

\section{Ethical considerations}

The study was non-invasive, and participants bore no financial burden to participate in the study. Permission and ethical approval to undertake the study was obtained from the Ethics Review Committee of the State Ministry of Health. Participants were informed about the nature of the study, assured of confidentiality and anonymity before voluntarily signing a consent form. Participants diagnosed with a mood or anxiety disorder were counselled and subsequently referred to a mental health specialist within the facility.

\section{Procedure}

Permission was obtained from the managing team at the Out-Patient HIV/AIDS Clinic to recruit participants. Participants satisfying the study inclusion criteria were approached to discuss the study protocol. An information sheet on the purpose and procedure of the study was provided for each participant. Written informed consent was obtained from each participant, assuring confidentiality and anonymity. 
Participants were systematically sampled using the daily clinic list as a sample frame. Each participant was administered the designed study questionnaire, the MINI and the Morisky 8-item questionnaire. Double sampling was avoided by tagging case records. Recruitment took place between April and August 2015.

\section{Data management}

Data were analyzed using the Statistical Package for Social Sciences (SPSS) version 21. Descriptive statistics were used to summarize data and are presented in Tables. For the purpose of bivariate and multivariate analysis, the main outcome variable - adherence to antiretroviral medications was dichotomized into 'poor adherence' (equivalent to low adherence on the MMAS-8) and 'good adherence' (which comprised moderate and high adherence on MMAS-8). For the main exposure variable, having any diagnosis of mood or anxiety disorder on the MINI, was dichotomized into 'mood/anxiety disorder present' or 'mood/anxiety disorder absent'.

Bivariate testing was performed using chi-squared tests and multivariate analysis was conducted with data entered into a binary logistic regression model with poor/good adherence as the outcome of interest. Level of significance was set a priori at $p<0.05$.

\section{Results}

\section{Socio-demographic characteristics of participants}

The mean age (SD) of the participants was 40.41 (9.76) years, with ages ranging between 18 and 64 years. Three hundred and eleven participants (75.9\%) were female, while one hundred and ninety-eight (48.3\%) had at least a secondary-level education. Two hundred and eighteen (53.1\%) participants were either married or cohabiting. Most participants $(n=353$; $86.1 \%)$ were employed. The mean monthly income $( \pm$ SD) was $\$ 43.08$ ( \pm 36.74), with range between $\$ 8$ and $\$ 277$ (Table 1).

\section{Clinical characteristics of participants}

The mean duration (SD) since diagnosis of HIV was 51.98 (28.06) months, with a range between 4 and 144 months. The mean duration (SD) on HAART was 41.69 (24.66) months, with a range between 3 and 108 months. Three hundred and forty-four (83.9\%) participants had CD4+ count of at least 200 cells $/ \mathrm{mm}^{3}$. The mean CD4+ cell count (SD) was 359.37 (171.82) cells $/ \mathrm{mm}^{3}$, with range between 64 to $953 \mathrm{cell} / \mathrm{mm}^{3}$. Ninety $(22.0 \%)$ participants had a current history of physical comorbidity or co-infection (Table 2).

\section{Prevalence and pattern of mood and anxiety disorders among participants}

One hundred and twenty-nine participants (31.5\%) were diagnosed with at least a mood or anxiety disorder using
Table 1. Socio-demographic characteristics of participants

\begin{tabular}{|c|c|c|}
\hline Variable & $\begin{array}{l}\text { Frequency } \\
(N=410)\end{array}$ & $\begin{array}{c}\text { Percentage } \\
\text { (\%) }\end{array}$ \\
\hline \multicolumn{3}{|l|}{ Age (years) } \\
\hline $18-30$ & 70 & 17.1 \\
\hline $31-40$ & 151 & 36.8 \\
\hline $41-50$ & 118 & 28.8 \\
\hline $51-64$ & 71 & 17.3 \\
\hline \multicolumn{3}{|l|}{ Gender } \\
\hline Male & 99 & 24.1 \\
\hline Female & 311 & 75.9 \\
\hline \multicolumn{3}{|l|}{ Educational status } \\
\hline No formal education & 12 & 2.9 \\
\hline Primary & 158 & 38.6 \\
\hline Secondary & 198 & 48.3 \\
\hline Tertiary & 42 & 10.2 \\
\hline \multicolumn{3}{|l|}{ Marital status } \\
\hline Never married & 64 & 15.7 \\
\hline Married/cohabiting & 218 & 53.1 \\
\hline Widowed & 80 & 19.5 \\
\hline Divorced/separated & 48 & 11.7 \\
\hline \multicolumn{3}{|l|}{ Having children } \\
\hline Yes & 326 & 79.5 \\
\hline No & 84 & 20.5 \\
\hline \multicolumn{3}{|l|}{ Living status } \\
\hline Lives alone & 42 & 10.2 \\
\hline Lives with others & 368 & 89.8 \\
\hline \multicolumn{3}{|l|}{ Employment status } \\
\hline Employed & 353 & 86.1 \\
\hline Unemployed & 57 & 13.9 \\
\hline \multicolumn{3}{|c|}{ Average monthly income (\$) } \\
\hline $0-30$ & 223 & 54.4 \\
\hline $31-300$ & 187 & 45.6 \\
\hline
\end{tabular}

the MINI. Among the 129 participants, 96 (23.4\%) were diagnosed with mood disorders, while 33 (8.1\%) had anxiety disorders. Major depressive disorder was the commonest mood disorder $(n=76 ; 18.5 \%)$, while generalized anxiety disorder was the commonest anxiety disorder $(n=8 ; 2.0 \%)$ (Table 3$)$.

\section{Pattern of adherence and correlates of poor adherence to HAART}

One hundred and fifty-one (36.8\%) participants reported low medication adherence. Most participants $(n=195$; $47.6 \%)$ reported a moderate adherence to medications, while $64(15.6 \%)$ participants had a high adherence to medications. 
Table 2. Clinical characteristics of participants

\begin{tabular}{|c|c|c|}
\hline Variable & $\begin{array}{l}\text { Frequency } \\
(N=410)\end{array}$ & $\begin{array}{c}\text { Percentage } \\
\text { (\%) }\end{array}$ \\
\hline \multicolumn{3}{|c|}{ Duration since HIV diagnosis (months) } \\
\hline $0-48$ & 253 & 61.7 \\
\hline $49-144$ & 157 & 38.3 \\
\hline \multicolumn{3}{|c|}{ Duration on HAART (months) } \\
\hline $0-48$ & 307 & 74.9 \\
\hline $49-108$ & 103 & 25.1 \\
\hline \multicolumn{3}{|c|}{ Presence of medical co-morbidity } \\
\hline Yes & 90 & 22 \\
\hline No & 320 & 78 \\
\hline \multicolumn{3}{|c|}{ CD4+ count (cell/mm $\left.\mathrm{mm}^{3}\right)$} \\
\hline$<200$ & 66 & 16.1 \\
\hline$\geq 200$ & 344 & 83.9 \\
\hline
\end{tabular}

Table 3. Prevalence and pattern of psychiatric morbidity

\begin{tabular}{l|c|c}
\hline Variable & $\begin{array}{c}\text { Frequency } \\
(N=410)\end{array}$ & $\begin{array}{c}\text { Percentage } \\
(\%)\end{array}$ \\
\hline $\begin{array}{l}\text { Any mood and/or anxiety } \\
\text { disorder present }\end{array}$ & 129 & 31.5 \\
\hline $\begin{array}{l}\text { Mood disorders } \\
\begin{array}{l}\text { Major depressive } \\
\text { disorders }\end{array}\end{array}$ & 96 & 23.4 \\
\hline \begin{tabular}{l} 
Dysthymic disorder \\
\hline $\begin{array}{l}\text { Bipolar affective } \\
\text { disorder }\end{array}$
\end{tabular} & 12 & 18.1 \\
\hline \begin{tabular}{l} 
Anxiety disorders \\
\hline Panic disorder
\end{tabular} & 33 & 2.9 \\
\hline $\begin{array}{l}\text { Post-traumatic stress } \\
\text { disorder (PTSD) }\end{array}$ & 7 & 1.7 \\
\hline Social phobia & 5 & 1.2 \\
\hline $\begin{array}{l}\text { Obsessive compulsive } \\
\text { disorder (OCD) }\end{array}$ & 3 & 0.7 \\
\hline Agoraphobia & 3 & 0.7 \\
\hline $\begin{array}{l}\text { Generalized anxiety } \\
\text { disorder (GAD) }\end{array}$ & 8 & 2.0 \\
\hline $\begin{array}{l}\text { No mood and/or anxiety } \\
\text { disorder present }\end{array}$ & 252 & 68.5 \\
\hline
\end{tabular}

There were no significant associations between gender ( $p=0.73)$, marital status $(p=0.06)$, area of residence $(p=0.52)$, living status $(p=0.39)$, employment status $(p=0.24)$, physical comorbidity $(p=0.05)$, and adherence to HAART. Participants with a CD4 cell count below 200 cells $/ \mathrm{mm}^{3}$ were at least thrice as likely to report poor adherence to HAART $(\mathrm{OR}=3.23$; 95\% CI: 1.81-5.80; $p<0.001)$. Similarly, participants diagnosed with a mood or anxiety disorder were significantly more likely to report poor adherence to antiretroviral therapy $(\mathrm{OR}=17.89$; 95\% CI: 10.28-31.38; $p<0.001$ ) (Table 4).

On multivariate analyses, the presence of a mood or anxiety was found to significantly predict poor adherence to HAART among PLWHA (AOR = 16.45; 95\% CI: 9.69-27.92; $p<0.001)$.

\section{Discussion}

\section{Main findings}

Poor adherence to HAART was common among patients attending the Out-Patient HIV/AIDS Clinic. In addition, mood and anxiety disorders were found to be common among the participants. Major depression, dysthymia were common mood disorders diagnosed, while generalized anxiety disorder, post-traumatic stress disorder, and panic disorders were common anxiety disorders. Poor adherence to HAART was associated with a low CD4+ count and having any mood or anxiety disorder. The effect of having a mood or anxiety disorder on poor adherence to HAART was slightly attenuated after controlling for the CD4+ level.

\section{Prevalence and pattern of mood and anxiety disorders}

The prevalence of a major depressive disorder among PLWHA was found to be $18.0 \%$. This is a higher percentage than the rate of $3.3 \%$ (lifetime prevalence) of major depression reported in general adult populations in Nigeria [29], and is consistent with other studies reporting higher rates of depressive disorder or symptoms amongst PLWHA, compared to the general population $[7,8]$. A recent review of prevalence rates of depressive symptoms or disorder among PLWHA in sub-Saharan Africa showed that rates vary due to ascertainment criteria. They report that on average studies utilizing diagnostic tools have an average prevalence rate of $18 \%$, which is in concordance with our study, while those using rating scales showed an average rate of $31.2 \%$ [30]. Depression is associated with immune suppression and other poorer health-related outcomes in studies of individuals with and without chronic diseases [31, 32]. Additionally, there is an evidence that in persons living with HIV/AIDS, depression is commoner in females [7, 33, 34], which is consistent with the fact that majority of the participants in this study were females.

A small minority were diagnosed with dysthymia and bipolar disorder. Though dysthymia has been reported among a sample in the USA as a comorbid of major depressive disorder, unlike the scenario from our survey where dysthymia was diagnosed with no other neuro-psychiatric disorder [35]. Dysthymia has been reported to adversely affect medication adherence, particularly in women [36]. We also noted that the prevalence of bipolar disorder in this cohort was low when compared to the rate of $8 \%$ from a study in the Brazil [37].

Anxiety disorders were diagnosed in about $8.0 \%$ of the participants in this study, which exceeds the $5.7 \%$ lifetime 
Table 4. Correlates of poor adherence to antiretroviral medications

\begin{tabular}{|c|c|c|c|}
\hline \multirow[t]{2}{*}{ Variable } & \multicolumn{2}{|c|}{ Medication adherence } & \multirow[t]{2}{*}{ Statistic } \\
\hline & Poor & Good & \\
\hline \multicolumn{4}{|l|}{ Gender } \\
\hline Male & 35 & 64 & \multirow[t]{2}{*}{$\mathrm{X}^{2}=0.122, p=0.73$} \\
\hline Female & 116 & 195 & \\
\hline \multicolumn{4}{|l|}{ Area of residence } \\
\hline Urban & 129 & 227 & \multirow[t]{2}{*}{$\mathrm{X}^{2}=0.409, p=0.52$} \\
\hline Rural & 22 & 32 & \\
\hline \multicolumn{4}{|l|}{ Living status } \\
\hline Living alone & 18 & 24 & \multirow[t]{2}{*}{$\mathrm{X}^{2}=0.73, p=0.39$} \\
\hline Living with others & 133 & 235 & \\
\hline \multicolumn{4}{|l|}{ Marital status } \\
\hline Single, separated, widowed & 80 & 112 & \multirow[t]{2}{*}{$\mathrm{X}^{2}=3.63, p=0.06$} \\
\hline Married, cohabiting & 71 & 147 & \\
\hline \multicolumn{4}{|l|}{ Employment status } \\
\hline Employed & 126 & 227 & \multirow[t]{2}{*}{$X^{2}=1.44, p=0.24$} \\
\hline Unemployed & 25 & 32 & \\
\hline CD4+ cell count & & & $\mathrm{X}^{2}=19.115, p<0.001$ \\
\hline$<200$ cells $/ \mathrm{mm}^{3}$ & 40 & 26 & \multirow{2}{*}{$\begin{aligned} \mathrm{OR} & =3.23 \\
95 \% \mathrm{Cl} & =1.81-5.80\end{aligned}$} \\
\hline$\geq 200$ cells $/ \mathrm{mm}^{3}$ & 111 & 233 & \\
\hline \multicolumn{4}{|l|}{ Physical co-morbidity } \\
\hline Present & 41 & 49 & \multirow[t]{2}{*}{$\mathrm{X}^{2}=3.774, p=0.05$} \\
\hline Absent & 110 & 210 & \\
\hline Mood and/or anxiety disorder present & & & $\mathrm{X}^{2}=144.350, p<0.001$ \\
\hline Yes & 102 & 27 & \multirow{2}{*}{$\begin{array}{c}\mathrm{OR}=17.89 \\
95 \% \mathrm{Cl}=10.28-31.38\end{array}$} \\
\hline No & 49 & 232 & \\
\hline
\end{tabular}

prevalence rate of any anxiety disorder in the National Mental Health Surveys (NMHS) [29]. Noteworthy is the fact that in the NMHS, 5.4\% of the participants were diagnosed of specific phobias but virtually no cases of generalized anxiety, panic, or post-traumatic stress disorders were identified [29]. In contrast, this study identified generalized anxiety disorder as the commonest anxiety disorder with panic and post-traumatic stress disorder to follow. The prevalence of anxiety disorders in this study is similar to prevalence rates between $7.0 \%$ and $8.1 \%$ reported in other studies among persons living with HIV/AIDS in Africa [5, 38], though rating scales screening for anxiety symptoms report higher rates [13].

\section{Prevalence of poor adherence to highly active antiretroviral therapy}

This study found the rate of poor adherence to HAART to be $36.8 \%$. This is slightly higher than reported prevalence rate of poor adherence to ART found in previous studies $[18,22]$. Studies conducted in more developed countries report better adherence to ART, and may reflect better awareness of the benefits of HAART as well as fewer logistic constraints, unlike in developing countries where transport problems, lack of funds to access healthcare services, or treatment payment for co-morbid illness [39].

People living with HIV/AIDS who were poorly adherent to ART had significantly lower mean CD4+ cell count and our findings were consistent with earlier reports [40]. However in Australia, Sternhell and Corr found no significant relationship between CD4+ cell count and poor adherence to antiretroviral medications [19]. Notably, the CD4+ cell count is a predictor of immunological response to antiretroviral treatment in PLWHA [41]. Indeed, the immunological response to ART is usually characterized by a CD4+ cell increase from baseline levels [41]. Therefore, the CD4 cell response is significantly influenced by the level of adherence to HAART. This is important not only at the time of initiation of treatment but also at the phase of treatment maintenance. Accordingly, the consequences of incomplete adherence to antiretroviral treatment include increased risk of drug resistance as well as increased morbidity and mortality. 


\section{Correlates of poor adherence to highly active antiretroviral therapy}

Participants diagnosed with any DSM-IV mood or anxiety disorder were nearly 16 times more likely to be poorly adherent to medications. The findings from this study are in agreement with the evidence from other studies that have linked a mental comorbidity, especially mood disorders with poor adherence to HAART [18, 21, 22, 40, 42]. This therefore supports the need to address mental health problems in order to improve medication adherence and overall clinical outcomes in people living with HIV/AIDS. Several factors have being known to influence adherence to HAART $[43,44]$, with psychiatric morbidity being a well-established factor that has been reported in the previous studies [18, 21, 22, 40, 42]. Persons living with HIV/AIDS may experience a lack of desire to take medications as part of depressive symptomatology. Furthermore, cognitive dysfunction manifesting as forgetfulness may lead to poor medication adherence. Patients may also stop taking their medications as a means of deliberate self-harm. These findings therefore suggest the need for physicians managing PLWHA to consider psychological maladjustment to the disease as an important aspect of patient management, as this would improve treatment adherence in the long run. In addition, these findings also suggest that issues regarding the mental health needs of people living with HIV/AIDS are of major public health concern. Therefore, they should be prioritized as much as possible [45-47].

\section{Limitations}

Our findings should be interpreted with the following limitations in mind. First, the study design was crosssectional, and it would be impossible to decide if in all cases a diagnosis of HIV/AIDS preceded the onset of mood and anxiety symptoms to determine direction of causality. Second, we did not assess for other factors (other psychological illnesses, socio-cultural factors (e.g. stigma), personality and coping styles), which may contribute to poor adherence. Third, medication adherence was determined using a self-report measure. This modality tends to result in an underestimation of the magnitude of poor adherence. Fourthly, persons who could not understand English language were excluded, this might have biased our study findings.

\section{Conclusions}

This study confirms that poor adherence to HAART is common among PLWHA in Nigeria. PLWHA report a mood and anxiety disorders that include major depression, dysthymia, and bipolar disorder. Generalized anxiety disorder, panic, and post-traumatic disorder were anxiety disorders reported. Having any DSM-IV mood or anxiety disorder was associated with a 16-fold increased risk of poor adherence to HAART.

\section{Conflict of interest}

The authors declare no potential conflicts of interest with respect to the research, authorship, and/or publication of this article.

\section{References}

1. Joint United Nations Program on HIV/AIDS. UNAIDS report on the global AIDS epidemic, 2013.

2. Federal Ministry of Health [Nigeria]. National HIV \& AIDS and Reproductive Health Survey, 2012 (NARHS Plus). Fmoh, Abuja 2013.

3. National Population Commission. Population and housing census of the Federal Republic of Nigeria, 2006.

4. Brandt R. The mental health of people living with HIV/AIDS in Africa: a systematic review. Afr J AIDS Res 2009; 8: 123-133.

5. Els C, Boshoff W, Scott C, et al. Psychiatric co-morbidity in South African HIV/AIDS patients. South African Med J 1999; 89: 992-995.

6. Freeman M, Nkomo N, Kafaar Z, Kelly K. Mental disorder in people living with HIV/AIDS in South Africa. South African J Psychol 2008; 38: 489-500.

7. Chikezie UE, Otakpor AN, Kuteyi OB, James BO. Depression among people living with human immunodeficiency virus infection/acquired immunodeficiency syndrome in Benin City, Nigeria: a comparative study. Niger J Clin Pract 2013; 16: 238-242.

8. Adewuya AO, Afolabi MO, Ola BA, et al. Psychiatric disorders among the HIV-positive population in Nigeria: a control study. J Psychosom Res 2007; 63: 203-206.

9. Sebit MB, Tombe M, Siziya S, et al. Prevalence of HIV/AIDS and psychiatric disorders and their related risk factors among adults in Epworth, Zimbabwe. East Afr Med J 2003; 80: 503-512.

10. Sulyman D, Abiodun OA, Yussuf AD. Psychiatric disorders among People Living with HIV/AIDS attending out-patient clinics at University of Ilorin Teaching Hospital, Nigeria. Trop J Heal Sci 2012; 19: 12-17.

11. Olley BO, Gxamza F, Seedat S, et al. Psychopathology and coping in recently diagnosed HIV/AIDS patients - the role of gender. South African J Psychol 2004; 10: 21-24.

12. Nebhinani N, Mattoo SK, Wanchu A. HIV stigma and specified correlates in North India. Indian J Psychol Med 2012; 34: 324-331.

13. Nel A, Kagee A. The relationship between depression, anxiety and medication adherence among patients receiving antiretroviral treatment in South Africa. AIDS Care 2013; 25: 948-955.

14. Adewuya AO, Afolabi MO, Ola BA, et al. Relationship between depression and quality of life in persons with HIV infection in Nigeria. Int J Psychiatry Med 2008; 38: 43-51.

15. Ogbuji QC, Oke AE. Quality of life among persons living with HIV infection in Ibadan, Nigeria. Afr J Med Med Sci 2010; 39: 127-135.

16. Arnsten J, Demas P, Farzadegan H, et al. Antiretroviral therapy adherence and viral suppression in HIV-infected drug users: comparison of self-report and electronic monitoring. Clin Infect Dis 2001; 33: 1417-1423.

17. Gifford A, Bormann J, Shively M, et al. Predictors of self-reported adherence and plasma HIV concentrations in patients on multidrug antiretroviral regimens. J Acquir Immune Defic Syndr 2000; 23: 386-395.

18. Adewuya AO, Afolabi MO, Ola BA, et al. The effect of psychological distress on medication adherence in persons with HIV infection in Nigeria. Psychosomatics 2010; 51: 68-73.

19. Sternhell PS, Corr MJ. Psychiatric morbidity and adherence to antiretroviral medication in patients with HIV/AIDS. Aust N Z J Psychiatry 2002; 36: 528-533.

20. Vranceanu AM, Safren SA, Lu M, et al. The relationship of posttraumatic stress disorder and depression to antiretroviral medication adherence in persons with HIV. AIDS Patient Care STDS 2008; 22: $313-322$ 
21. Amberbir A, Woldemichael K, Getachew S, et al. Predictors of adherence to antiretroviral therapy among HIV-infected persons: a prospective study in Southwest Ethiopia. BMC Public Health 2008; 8: 265.

22. Olisah VO, Baiyewu O, Sheikh TL. Adherence to highly active antiretroviral therapy in depressed patients with HIV/AIDS attending a Nigerian university teaching hospital clinic. Afr J Psychiatry (Johannesbg) 2010; 13: 275-279.

23. Sheehan DV, Lecrubier Y, Sheehan KH, et al. The Mini-International Neuropsychiatric Interview (M.I.N.I.): the development and validation of a structured diagnostic psychiatric interview for DSM-IV and ICD-10. J Clin Psychiatry 1998; 59 Suppl 20: 22-33.

24. Adewuya AO, Ola BA, Aloba OO, et al. Alcohol use disorders among Nigerian university students: Prevalence and socio-demographic correlates. Niger J Psychiatry 2007; 5: 5-9.

25. Sulyman D, Abiodun OA, Yussuf AD. Detection of psychiatric disorders by physicians attending to People Living with HIV/AIDS (PLWHA) in a Nigeria University Teaching Hospital. J Biol Agric Healthcare 2013; 3: 92-97.

26. Morisky D, Ang A, Krousel-Wood M, Ward H. Predictive Validity of a Medication Adherence Measure in an Out-patient Setting. J Clin Hypertens (Greenwich) 2008; 10: 348-354.

27. Adelufosi AO, Adebowale TO, Abayomi O, Mosanya JT. Medication adherence and quality of life among Nigerian outpatients with schizophrenia. Gen Hosp Psychiatry 2002; 34: 72-79.

28. Mahaye S, Mayime T, Nkosi S, et al. Medication adherence of psychiatric patients in an outpatient setting. African J Pharm Pharmacol 2012; 6: 608-612.

29. Gureje O, Lasebikan V, Kola L, et al. Lifetime and 12-month prevalence of mental disorders in the Nigerian Survey of Mental Health and Well-Being. Br J Psychiatry 2006; 188: 465-471.

30. Nakimuli-Mpungu E, Bass JK, Alexandre P, et al. Depression, alcohol use and adherence to antiretroviral therapy in sub-saharan africa: a systematic review. AIDS Behav 2012; 16: 2101-2118.

31. Ickovics JR, Hamburger ME, Vlahov D, et al. Mortality, CD4 cell count decline, and depressive symptoms among HIV-seropositive women: longitudinal analysis from the HIV epidemiology research study. J Am Med Assoc 2011; 285: 1466-1474.

32. Herbert T, Cohen S. Depression and immunity: a meta-analytic review. Psychol Bull 1993; 113: 472-486.

33. Olley BO, Seedat S, Nei DG, Stein DJ. Predictors of major depression in recently diagnosed patients with HIV/AIDS in South Africa. AIDS Patient Care STDS 2004; 18: 481-487.

34. Kaharuza FM, Bunnell R, Moss S, et al. Depression and CD4 cell count among persons with HIV infection in Uganda. AIDS Behav 2006; 10 (Suppl 4): 105-111.

35. Gaynes BN, O’Donnell J, Nelson E, et al. Psychiatric comorbidity in depressed HIV-infected individuals: common and clinically consequential. Gen Hosp Psychiatry 2015; 37: 277-282.

36. Turner BJ, Fleishman JA. Effect of dysthymia on receipt of HAART by minority HIV-infected women. J Gen Intern Med 2006; 21 : 1235-1241

37. de Sousa Gurgel W, da Silva Carneiro AH, Barreto Rebouças D, et al Prevalence of bipolar disorder in a HIV-infected outpatient population. AIDS Care 2013; 25: 1499-1503.

38. Olagunju AT, Ogundipe OA, Erinfolami AR, et al. Toward the in tegration of comprehensive mental health services in HIV care: an assessment of psychiatric morbidity among HIV-positive individuals in sub-Saharan Africa. AIDS Care 2013; 25: 1193-1198.

39. Obiako OR, Muktar HM. Challenges of HIV treatment in resourcepoor countries: a review. Niger J Med 2010; 19: 361-368.

40. Ammassari A, Antinori A, Aloisi MS, et al. Depressive symptoms, neurocognitive impairment, and adherence to highly active antiretroviral therapy among HIV-infected persons. Psychosomatics 2004; 45: 394-402.
41. Abrogoua DP, Kablan BJ, Kamenan BAT, et al. Assessment of the impact of adherence and other predictors during HAART on various CD4 cell responses in resource-limited settings. Patient Prefer Adherence 2012; 6: 227-237.

42. Vanable PA, Carey MP, Blair DC, Littlewood RA. Impact of HIVrelated stigma on health behaviors and psychological adjustment among HIV-positive men and women. AIDS Behav 2006; 10: 473-482.

43. World Health Organization (WHO). Consolidated guidelines on the use of antiretroviral drugs for treating and preventing HIV infection: recommendations for a public health approach, 2013.

44. Chesney M. Factors affecting adherence to antiretroviral therapy. Clin Infect Dis 2000; 30 (Suppl 2): S171-S176.

45. Marcellin F, Spire B, Carrieri MP, Roux P. Assessing adherence to antiretroviral therapy in randomized HIV clinical trials: a review of currently used methods. Expert Rev Anti Infect Ther 2013; 11: 239-250.

46. Bolsewicz K, Debattista J, Vallely A, et al. Factors associated with antiretroviral treatment uptake and adherence: a review. Perspectives from Australia, Canada, and the United Kingdom. AIDS Care 2015; 27 : 1429-1438.

47. Chesney MA, Ickovics JR, Chambers DB, et al. Self-reported adherence to antiretroviral medications among participants in HIV clinical trials: The AACTG Adherence Instruments. AIDS Care 2000; 12: $255-266$ 